\title{
Medicalization Defined in Empirical Contexts - A Scoping Review
}

\author{
Wieteke van Dijk ${ }^{*}$, Marjan J. Meinders, Marit A.C. Tanke, Gert P. Westert, Patrick P.T. Jeurissen
}

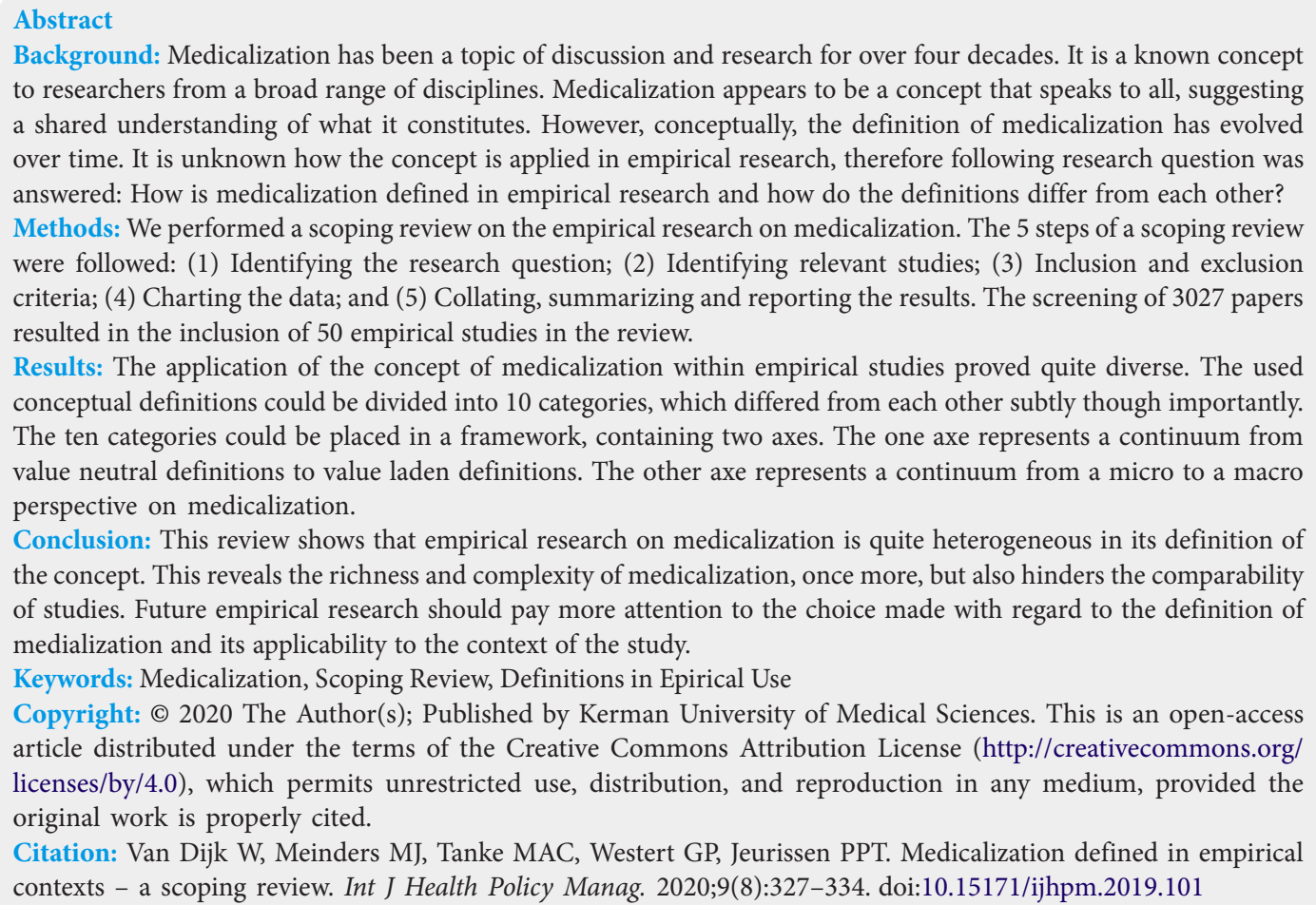

\section{Article History:}

Received: 17 April 2019

Accepted: 23 October 2019

ePublished: 21 December 2019

\section{Background}

While the definition and understanding of medicalization has evolved over time, there has never been a broad consensus on its meaning. ${ }^{1}$ The debate started in the seventies with the notion that medicine increasingly gained social control. ${ }^{2}$ Zola stated that society's explicit wish for medicine to use its controlling potential resulted in medicalization. ${ }^{3} \mathrm{He}$ stated that medicine was replacing the traditional institutions that 'shaped' society, such as religion and law. ${ }^{2}$ Ultimately, this resulted in more reliance on experts. ${ }^{3}$ Zola criticized the assumed neutrality of this process. ${ }^{3}$ According to Illich, medicine gained power at the expense of people's natural competences. ${ }^{4}$ This social control of medicine over people's lives led to iatrogenic effects. Illich considered physicians' imperialism central to this process. Although Illich never defined medicalization, he is generally understood as one of the first to address it and its consequences. Both Zola and Illich considered social control central to medicalization.

The feminist critique on medicalization centers also on social control as a central element, yet here the focus lay on medicalization resulting in professionals, traditionally men, gaining power and agency over women's health, bodies and reproductive processes. Medical care surrounding pregnancy and delivery is an example of a well-developed field within this literature, ${ }^{5,6}$ but the range of topics is extensive. ${ }^{7}$ While medicalization is seen as inseparably gendered by some, recently attention was drawn to the medicalization of male issues, such as erectile dysfunction, ${ }^{8}$ soldiers war trauma ${ }^{9}$ and male menopause. ${ }^{10}$

The conceptual understanding of medicalization has shifted over time. In 1992, Conrad defined medicalization as: "Medicalization consists of defining a problem in medical terms, using medical language to describe a problem, adopting a medical framework to understand a problem, or using a medical intervention to "treat" it" (p. 211). ${ }^{11}$ Here, Conrad placed the definitional aspect of medicalization at the core of its essence. Through the process of medicalization problems, and - if available - their solutions, come under the jurisdiction of medicine. Nonetheless, social control was not at the core of this influential definition per se.

During the past decades, a shift in the 'engines of medicalization' has been noticed, placing more emphasis 
on diverse contributors towards medicalization, such as industry and patients. ${ }^{12,13}$ This broader perspective served a more comprehensive understanding of medicalization. For example, it also provides the possibility to study positive effects of medicalization. ${ }^{14,15}$ On the other hand, Hofmann has argued that this resulted in medicalization becoming too much of an all-embracing term, and losing its critical value. ${ }^{16}$ He stated that medicalization has evolved over time from a critical perspective on the power-relations in medicine, to an almost all-compassing term involving all transformations in modern medicine. Furthermore, it has been argued that by focusing on the definitional issue of medicalization, the applied nature of medicine was overlooked. ${ }^{1}$

Parallel to the field of medicalization, adjacent research fields have developed, such as pharmaceuticalization and biomedicalization. Pharmaceuticalization is "the process by which social, behavioural or bodily discomforts are treated, or deemed to be in need of treatment/intervention, with pharmaceuticals by doctors, patients or both."17 Biomedicalization constitutes intensified medicalization, transformed and boosted due to techno scientific innovations. ${ }^{18}$ Both are conscious of the corporate interests of companies, technological changes, consumerism, the influence of the media and risk. ${ }^{19}$ Both processes define similar mechanisms to medicalization. Therefore, it is disputed whether either constitutes a new, unique process, ${ }^{18}$ or in fact represent a subset of medicalization (pharmaceuticalization) or an intensified form of medicalization (biomedicalization). ${ }^{20}$

The literature that focused on medicalization is multifaceted and addresses many topics. Most of the work is conceptual, discussing its occurrence and essence. Empirical studies that systematically gather and analyze data are relatively rare. Such empirical studies mostly use qualitative methods, although a small sample of quantitative studies is available. ${ }^{21-23}$ A large share of the literature consists of 'discussion papers': well-informed and well-founded articles that discuss the medicalized status of a problem or situation. A non-exhaustive list of topics include the medicalization of sleep ${ }^{24}$; hyperactive behavior in children ${ }^{25,26}$; self-injuring acts ${ }^{27}$; and risks and genetic markers. ${ }^{28,29}$ Although discussion papers support the conceptual development, a major drawback is that their empirical rigorousness is uncertain. This review is among the very first to focus on the empirical translation of the concept of medicalization.

The growing body of conceptual literature on medicalization underlines the necessity of a clear understanding of its use in empirical research. How medicalization was used in empirical research has not been reviewed yet. Because the definition of the subject under study is crucial to a study, as it shapes the researchers perspective and nudges the interpretations of its results, this is a logical starting point for a review. Therefore, we categorized the various definitions used in empirical research and illustrate their similarities and differences. It is unknown whether the empirical application of medicalization is as diverse as the conceptual work, or whether the combined empirical work contributes to a shared understanding of medicalization and its mechanisms. This review aims to assist with a first step in this direction.
Data and Methods

Given the aims of this study, a scoping review research design was adopted. Scoping reviews are characterized by the intention to 'map' a certain research and find what possible unanswered questions remain. ${ }^{30}$ We used the framework of Arksey and O'Malley for performing scoping reviews. ${ }^{31}$

\section{Identifying the Research Question}

The process of a scoping review is not linear but iterative, encouraging researchers to be reflexive and repeat a step when necessary. ${ }^{31}$ This has proven to be very relevant to this exercise. We started with our research question: 'What is empirically known about medicalization?' First, all peerreviewed research that primarily investigates medicalization was collected.

While performing these steps we discovered that studies that addressed medicalization used different definitions for a wide variety of topics. This hinders comparability. Further, we realized that many of the quantitative studies that form the core of the empirical work on medicalization, used the concept of medicalization as an interpretive frame, rather than study the essence and workings of medicalization in its actual progress. An operationalization of medicalization was not provided by any of the included studies. Thus, we were not able to test the actual construct validity of these definitions. Thus synthesizing the results of our empirical research with one meta-analysis is impossible and undesirable. Replication, comparability and robustness are difficult in any research field, but qualitative work is largely incompatible with it. ${ }^{32}$ Nonetheless, the results of our search exemplified that there is a robust amount of empirical research with medicalization as its subject. As said, the used definitions of the medicalization varied strongly. To further advance the concept, insight into the within-study variations were required. Empirical studies are relevant because they do apply the concept to a real life situation, indirectly testing its robustness. Therefore, the research question was iteratively adjusted to: 'How is medicalization defined in empirical research and how do the definitions differ from each other?'

\section{Identifying Relevant Studies}

A systematic search strategy was conducted in April 2014 in PubMed $^{\circledR}$, Web of Science ${ }^{\circledR}$, Sociological Abstracts ${ }^{\circledR}$, PsychInfo $^{\circledR}$, EMBASE $^{\circledR}$, Philosophers Index ${ }^{\circledR}, \mathrm{EBSCO}^{\circledR}$, and CINAHL $^{\circledR}$. The search strings were developed in cooperation with a librarian specialized in systematic reviews. References including any of the following keywords in title or abstract: "medicalization" OR "biomedicalization" OR "demedicalization" OR "biomedicalizations" OR "medicalizations" OR "demedicalizations." Pharmaceuticalization was not one of the search words, because pharmaceuticalization is often stated to be an intensified form of medicalization, whereas biomedicalization was included as a subset of medicalization..$^{20}$ Searches were conducted in both British and American spelling. The search string was identical for all databases. In addition, the first author (WvD) hand-searched several journals for additional results, to validate the search string. This resulted in no additional references. Duplicates, non- 
English references, and non-peer reviewed articles (editorials, letters, conference papers, book chapters, and dissertations) were excluded.

\section{Inclusion Criteria}

In the first phase of the screening process, $\mathrm{WvD}$ screened for eligibility of the references on title and abstract. In the second phase, WvD and NdV (research assistant) screened the remaining full-texts for eligibility.

In phase one, articles that present original, empirical research with medicalization as main research topic were included. General discussions, anecdotic evidence, secondary analysis of existing data or single case studies were excluded. We chose to limit the period an article could address to the period post-World War II. We also limited the inclusion to studies conducted in high-income countries. Whether the country was a high-income country was determined with the World Bank website (accessed on February 3, 2015). Indeed, Bell and Figert argue that the emphasis within the medicalization debate lies largely on the Western context, limiting its perspective. ${ }^{19}$ We agree, yet we are convinced that medicalization can consist of something entirely different in the context of limited resources and little medical assistance in low income countries, compared to medicalization within affluent countries with abundant access to medical care. To improve the understanding and mechanisms of medicalization in the context of countries with few healthcare recourses was not the subject of this review. Finally, the review was restricted to peer-reviewed articles written in English.

\section{Charting the Data}

In phase 2 the requirement of a definition of medicalization was added. Studies that failed to report how they defined medicalization were excluded. During this process, WvD and $\mathrm{NdV}$ met regularly for discussion. Some studies provided an overview of the medicalization debate, mentioning several definitions, but did not formally finalize the definition they would use. In such cases, we chose to retrieve definition last mentioned, because this would be what the discussion of the literature would work towards. Definition were copied literately from the studies. An overview of the data retracted in this process can be found in the supplemental material of this article.

\section{Collating, Summarizing and Reporting the Results}

WvD and MM (the second author) studied the retrieved definitions and independently grouped them into categories. Afterwards, they met and discussed the categories. The categorization of the definitions happened on a basis of semantics, signal words and phrases. To order the categories in the resulting figure, $\mathrm{WvD}$ and MACT met several times to discuss the relative position the categories. At first a onedimension ordering was pursued, but this proved incapable to capture the variation. Discussion, resulted in a second dimension to the figure.

\section{Results}

The initial search resulted in 7308 potential articles of which
4281 were duplicates, resulting in 3027 unique articles. Of these 3027 article, 2977 were excluded for reasons mentioned in the methods section. 31 one empirical studies did not define medicalization. Figure 1 represents the identification and selection process.

\section{Allocation to a Framework Containing 2 Axes}

The resulting 50 definitions were charted into ten categories (Figure 2). Most included studies quote a definition or refer to known definitions. Conrad and Zola are most often mentioned. Few are represented more than once, only Barker, ${ }^{33-35}$ Clarke, ${ }^{36,37}$ and Vainionpaa \& Topo. ${ }^{10,38}$ Both works by Vainionpää and Topo belong to one definition category. The studies of Barker and Clarke \& Lang/Clarke were allocated to different categories.

Two definitions could not be allocated, because they combined distinctive elements from across the spectrum..$^{39,40}$ An overview of the 50 selected studies can be found in the supplemental material (Supplementary file 1, Table S1).

The ten categories were allocated in a framework containing 2 axes: one addressing the value position of the definition at stake and the other addressing its micro/macro focus. Definitions that are value-laden include a judgment of the consequences and desirability of the process of medicalization. Value-neutral definitions do not include such a judgment. Definitions with a micro focus concentrate on the individual. Definitions on the other axis concentrate on the societal implications of medicalizing a situation.

Table illustrates these ten categories. For each category, this table shows a definition from one of the included studies. For reasons of further clarification, this table provides a fictive illustration for each of these categories.

Neither, year of publication nor topic could be related to the categories. The 50 allocated studies were for the most part published after 2000. Several subjects are represented across the entire spectrum of the different categories, including pregnancy, children's behavioral problems, and cosmetic surgery. Medicalization of sleep is subject to studies on the ends of both axes. Geographically the North-American continent is dominant with 19 of studies conducted in the United States and 11 in Canada (separate analysis). Several European countries are represented: the United Kingdom

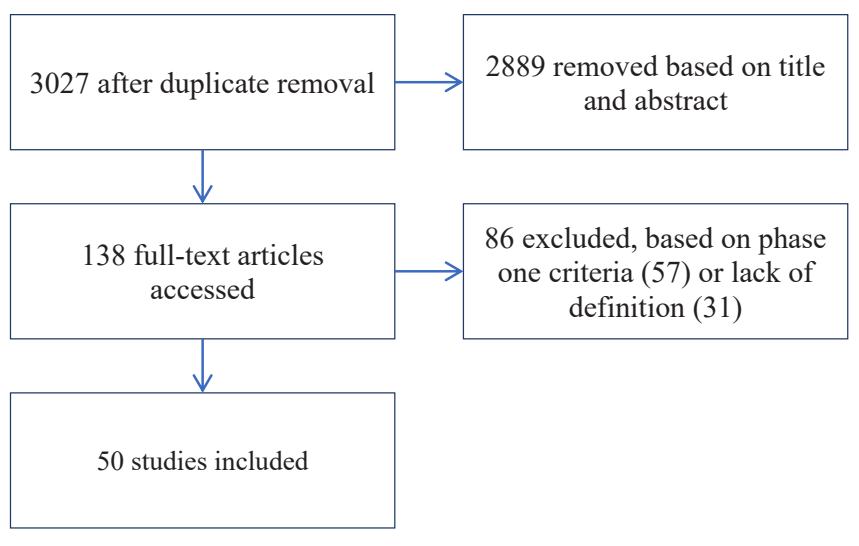

Figure 1. Selection Procedure of Included Studies. 


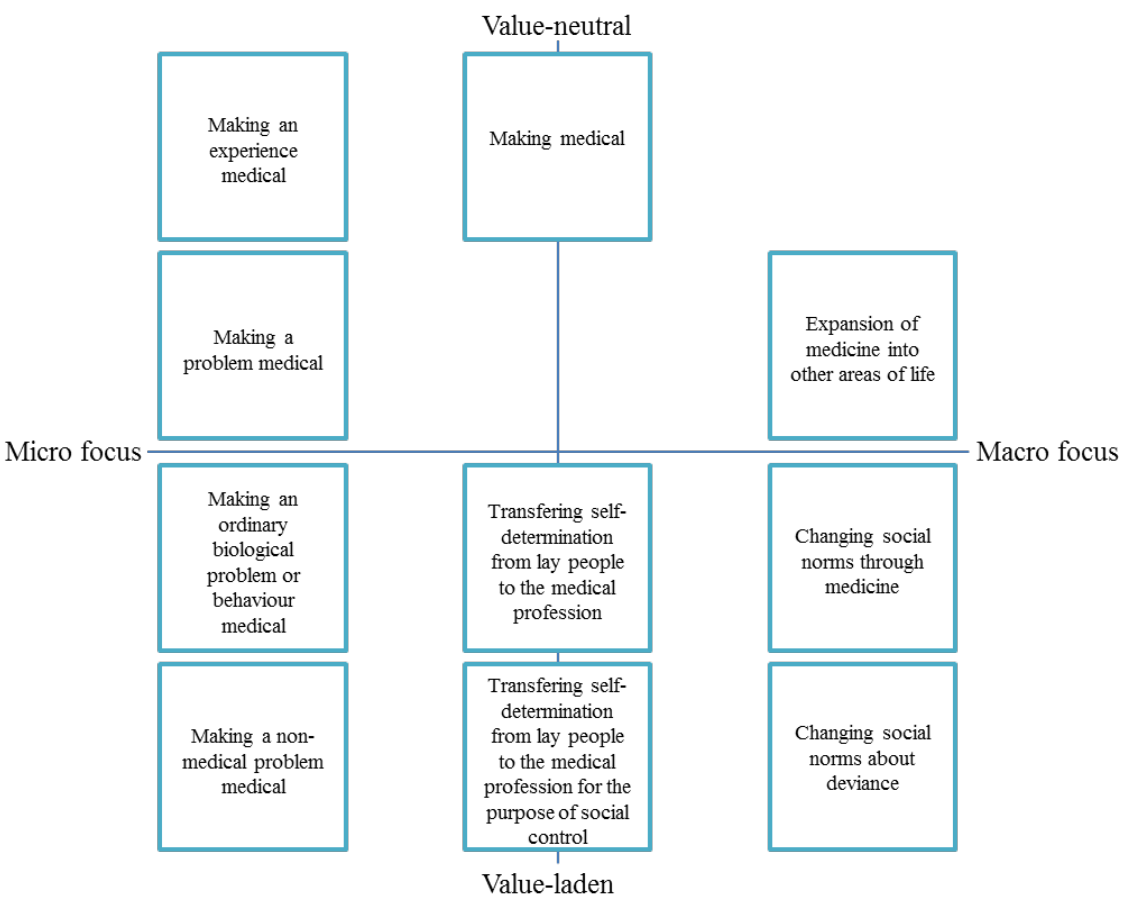

Figure 2. Framework of the Categories of Definitions of Medicalization Across the Axes of Micro/Macro Focus and Value-Neutral/Value-Laden.

(10); Finland (4); Sweden (2); the Netherlands (1); France (1); and Ireland (1). One study was conducted in New Zealand. For 1 study, the country of origin of the respondents could not be determined. ${ }^{41}$

\section{Ten Categories of Medicalization}

Each category is discussed with reference to Figure 2, starting with the four categories ranging from top left to bottom left. These 4 categories all have a micro perspective, but differ in the extent to which they are value-laden. The definition that is most value-neutral focuses on experiences and their medicalization. The next category concerns the medicalization of a problem: "Medicalization consists of defining a problem in medical terms, using medical language to describe a problem, adopting a medical framework to understand a problem, or using medical intervention to treat it." ${ }^{20}$ This definition is quoted from Conrad. ${ }^{11}$ In the third of these four definitions, the definition of medicalization requires for something ordinarily biological to be present to get medicalized: "Medicalization is the process by which formerly normal biological processes or behaviors come to be described, accepted, or treated as medical problems." ${ }^{2}$ Only the treatment of ordinary situations are stated to be medicalization. This makes it a less value-neutral definition than the previous category, because it makes an implicit distinction between ordinary and non-ordinary situations.

The fourth category defines medicalization as: "A process by which non-medical problems become defined and treated as medical problems, usually in terms of illnesses or disorders." ${ }^{\prime 6}$ Problems that were previously not regarded as medical in nature come to be medically treated. This definition makes a distinction between medical and non-medical problems, implicating that the difference between the two groups is apparent.
For other definitions, the other end of the horizontal axis is more distinctive, focusing on the macro outcomes of medicalization. This holds for the three categories on the right site of the framework. Here, medicalization: "refers to the ways in which medicine expands into new arenas." 38

Other definitions go one step further, including not only the expansion of medicine into other areas of life, but also subsequently changing the social norms surrounding it: "This refers to an intricate social process involving the dominance of biomedical paradigms and authoritarian models of healthcare in which illness experiences are understood as biological and individualistic." ${ }^{73}$ These definitions are more value-laden, as is represented by the other axis in the framework

The next category, in the right bottom of Figure 2, focuses on the changing norms surrounding deviance: "I use the term "medicalization" to refer to the process by which deviant acts (a) become understood to originate from a medical cause and are therefore perceived to be beyond an individual's control; and $(b)$ are believed to be treatable through medical knowledge and the application of techniques by medical experts." 75

The second axis concerns the values included in the definition. The remaining three categories are placed in the centre of Figure 2. The one end of this axis concerns the definitions that do not draw a (moral) judgment about the content or consequences of medicalization. When medicalization is defined as 'making medical' no consequence is predicted for society or the power-balance therein. Williams et al define medicalization as "(ideally) a non-judgmental term, referring simply to the process of "making medical." 83 According to this definition, everything that belongs to the jurisdiction of medicine was once medicalized.

When medicalization is defined as "the transfer of knowledge from the lay people to the medical profession for the purpose of social control," medicalization is perceived as 
Table. Overview of Categories of the Definitions of Medicalization, the Articles Utilizing Those Definitions, an Example as Used in One of the Articles and an (Fictive) Illustration

\begin{tabular}{|c|c|c|}
\hline $\begin{array}{l}\text { Distinctive Definition, } \\
\text { Answering the Question } \\
\text { 'What Constitutes } \\
\text { Medicalization?' }\end{array}$ & Studies & Definition Used \\
\hline Making medical & 42 & $\begin{array}{l}\text { "Medicalization is (ideally) a non-judgmental term, referring } \\
\text { simply to the process of 'making medical'" (Williams et al, }{ }^{42} \text { p. } \\
\text { 252). }\end{array}$ \\
\hline $\begin{array}{l}\text { Making an experience } \\
\text { medical }\end{array}$ & $33,37,41,44-47$ & $\begin{array}{l}\text { "'Medicalization,' or the processes by which an ever wider } \\
\text { range of human experiences come to be defined, experienced, } \\
\text { and treated as medical conditions" (Barker, }{ }^{33} \text { p. 21). }\end{array}$ \\
\hline
\end{tabular}

$\begin{array}{ll} & \text { "Medicalization consists of defining a problem in medical } \\ \text { Making a problem } & \text { terms, using medical language to describe a problem, } \\ \text { medical } & \text { adopting a medical framework to understand a problem, or } \\ & \text { using medical intervention to treat it" >quotes from Conrad, } \\ & \left.1992 \text { (Elston et al, }{ }^{50} \text { p. } 577\right) .\end{array}$

Making an ordinary biological process or behavior medical
"Medicalization is the process by which formerly normal biological processes or behaviors come to be described, accepted, or treated as medical problems" (Moloney et al, ${ }^{23}$ p. 1429).

Making a non-medical problem medical

"A process by which non-medical problems become defined and treated as medical problems, usually in terms of illnesses or disorders" >quotes Conrad, 2000 (Neiterman, ${ }^{60}$ p. 114).
Illustration

All of the illustrations

Signaling a rare case of feeling bloated as irritable bowel syndrome, a night of bad sleep as insomnia or normal-range shyness as social anxiety disorder

Attempting to improve a negative self-image by means of cosmetic surgery

Approaching the aging body through a medical perspective, attempting to repair natural decline

\section{Medical professionals attending} people who experience loneliness and prescribing antidepressants and/or welfare arrangements

Creating calm and teachable schoolchildren by neutralizing unwanted behavior with pharmaceuticals

expands into new arenas" (Vainionpää and Topo, ${ }^{38}$ p. 842).

"This refers to an intricate social process involving the through medicine
Changing social norms dominance of biomedical paradigms and authoritarian model of health care in which illness experiences are understood as biological and individualistic" (Thomas-McLean, ${ }^{73}$ p. 630).
Change in perspective about desirability of the birth of children with severe birth defects or chromosomal defects due to availability and acceptability of prenatal testing
"I use the term 'medicalization' to refer to the process by which deviant acts $(a)$ become understood to originate from

Changing social norms about deviance through 74,75 medicine

Transferring selfdetermination and decision-making from lay people to the medical profession a medical cause and are therefore perceived to be beyond an individual's control; and $(b)$ are believed to be treatable through medical knowledge and the application of techniques by medical experts" (Rafalovich, ${ }^{75}$ p. 26).

"The medical profession, on behalf of industrialism, has not only duped the public into believing that they have an effective and invaluable body of knowledge and skills but have created a dependence through the medicalization of life which has now taken away the public's right to self-care" (Calnan, ${ }^{77}$ p. 561).
Regarding criminal acts the result of sickness rather than badness

People changing their daily routine on doctors' orders to meet the conditions of their complex treatment regime, for example in case of hiv-infection or Parkinson's disease, while they felt more well and secure in their personal rhythm
Transferring selfdetermination and decision-making from lay people to the medical profession for the purpose of social control
[Medicalization is a] "process of social control whereby both deviant behavior and natural life events are reconstructed as illnesses or disorders and placed under the jurisdiction of the medical profession" (Hislop and Arber, ${ }^{80}$ p. 816).
Patients in long stay mental health care expected to live according to the institutional daily schedule, surrendering their privacy and autonomy to clinicians and other professionals

The definition and treatment of life problems, processes, or deviance in medical terms (Paramsee, ${ }^{40}$ p. 1342).

Medicalization of infertility, or its treatment as a pathological condition rather than a natural or social one (Bell, ${ }^{39}$ p. 631). 
an imperialist effort of the medical profession, overruling lay autonomy, representing the other end of this axis. This includes a strong power-related and value-laden consequence of medicalization as an integral aspect of the definition.

The definition that states that medicalization is the transfer of knowledge and decision-making from lay people to the medical profession is less value-laden. Calnan states: "The medical profession, on behalf of industrialism, has not only duped the public into believing that they have an effective and invaluable body of knowledge and skills but have created a dependence through the medicalization of life which has now taken away the public's right to self-care." ${ }^{77}$ Medicalization, in this definition, compromises the right of self-determination.

\section{Discussion}

This scoping review and the resulting framework (Figure 2) provide several insights on the composition and heterogeneity of medicalization research. Firstly, the actual research topics seem not to be related to the different categories of definitions of medicalization. For example, studies about sleep were present across several categories in the spectrum, including the two ends of the value axes. This illustrates that even within the research field of medicalization, the same subject can be studied from different (conceptual) angles. It also complicates the comparability of results. Secondly, in spite of diversity in definitions, the sources that the studies based their definitions upon were dominated by one author. In 20 of the 50 studies Conrad is either quoted or referred to, as a single author or in shared authorship. While Conrad's perspective on medicalization has evolved over the decades, his 1992 definition remains a point of reference in empirical work. ${ }^{11}$

These findings add up to an important discussion point. Medicalization research has a strong qualitative focus, explicating different aspects and nuances of the phenomenon. This review did not have the goal to disqualify this rich literature or to unify the perspective on the phenomenon. The goal was to map the definitions, to illustrate the diversity of the field. Differences between studies' definitions can be entirely justifiable because of the research question or focus of the study. However, it is nonetheless relevant to notice and be transparent about them. Since none of the studies provided an operationalization of their definition, it is impossible to reflect on the construct validity of medicalization in empirical research. This is another reason to press for transparency and reflection in future research. Furthermore, our research shows that scholars chose different conceptual angles. This variety also illustrates that empirical work will always be context dependent and will highly relate on the case study at issue.

Our research resulted in a framework that can be used by scholars to classify their work and that of others. Nonetheless, a framework like ours raises new questions. For example, the framework illustrates how definitions may vary in valueladenness. The process of medicalization results in people becoming patients. This might improve their social position and their health, but it might have a profound (possibly detrimental) effect on their life as well. Another critical remark can be made with regard to the micro/macro axis. A definition on the macro level can make it more difficult to identify the individual consequences on the micro-level. This can have important consequences for both research and policy-making. For example, if the focus lies solely on the negative macro consequences of a newly medicalized situation, for example its costs, individual benefits can easily be overlooked. Avoiding this problem by choosing the most neutral definition, 'the process of making medical', seems to address this problem. Yet, this definition is possibly too general to be of empirical use. This reveals a trade-off between specific and general definitions of medicalization. Further, as mentioned in the introduction, the conceptual definition of medicalization is crucial to a study, because it frames the perspective of the research team. What a researcher perceives as essential to medicalization, influences his or her perspective on the interpretation of the results. For example, when the influence and power of the medical profession is stated to be essential for the definition of medicalization, this probably influences the interpretation of the results. Subsequently, their understanding of health and healthcare are likely to differ from studies that use definitions focus on other elements.

\section{Limitations}

A limitation of this study is that the review process was guided by the empirical studies that were identified. It is not possible to conclude that every conceptual definition of medicalization has been applied. Furthermore, we did not address whether the chosen definition was the most valid one per study. It would require an in-depth analysis of each study to draw conclusions about the application of the used definition to the studies contexts and results. The sample of 50 studies was too big to perform these analyses. Therefore, we are unable to verify whether the methods and results per study agree with the allocation of the study in the framework. This makes it impossible to state anything about the empirical applicability of the definitions. Future research should pay attention to these difficulties and should be more responsive and reflective about the choices made within each study, also with regard to the chosen definition and its applicability to the research context.

With regard to the scoping exercise, we found 31 studies with medicalization as its subject that failed to define medicalization. We did not distillate the implicit definition from these studies, because we found this too sensitive for misinterpretation. Further, the grouping of the definitions and the charting of the figure were an interpretative exercise. This is both a strength and a possible weakness of this method. To minimize the risk, we discussed allocation of the definitions and the categories to the figure regularly within our project group. This resulted in a figure that all authors regarded as robust and representative for the included conceptual definitions.

\section{Implications for Future Research}

This scoping review showed that empirical research about medicalization has a broad scope. This portrays the richness and variety of the field. Nonetheless, we reveal that the understanding of what medicalization constitutes of differs as much within empirical studies as it does in the conceptual 
literature. To advance the understanding of the mechanisms of medicalization, future research should be attentive to these differences, defining their study subject accurately, to enable the further development of the concept and to connect the conceptual and the empirical literature.

\section{Acknowledgements}

We thank Nynke de Vries for her assistance in the review process.

\section{Ethical issues}

Not applicable.

\section{Competing interests}

Authors declare that they have no competing interests.

\section{Authors' contributions}

WVD, MJM, MACT, GPW, and PPTJ conceived and designed the review process and analysis. WVD and MJM collected the data. WVD and MJM performed the data analysis. All authors discussed the results and contributed to the final manuscript.

\section{Supplementary files}

Supplementary file 1 contains Table S1.

\section{References}

1. Davis JE. Medicalization, Social Control, and the Relief of Suffering. In: Cockerham W, ed. The New Blackwell Company to Medical Sociology. Singapore: John Wiley \& Sons Ltd; 2010:211-241.

2. Busfield J. The concept of medicalisation reassessed. Sociol Health IIIn. 2017;39(5):759-774. doi:10.1111/1467-9566.12538

3. Zola IK. Medicine as an institution of social control. Sociol Rev. 1972;20(4):487-504. doi:10.1111/j.1467-954X.1972.tb00220.x

4. Illich I. Limit to Medicine. Medical Nemesis: the Expropriation of Health. London - New York: Marion Boyars; 1995 [1976].

5. Barker KK. A ship upon a stormy sea: the medicalization of pregnancy. Soc Sci Med. 1998;47(8):1067-1076. doi:10.1016/s02779536(98)00155-5

6. Oakley A. The Captured Womb: A History of the Medical Care of Pregnant Women. Oxford: Basil Blackwell Publisher Ltd; 1984.

7. McHugh MC, Chrisler JC. The wrong prescription for women: how medicine and media create a "need" for treatments, drugs, and surgery. Santa Barbara: Praeger; 2015.

8. Wentzell E. How did erectile dysfunction become "natural"? A review of the critical social scientific literature on medical treatment for male sexual dysfunction. J Sex Res. 2017;54(4-5):486-506. doi:10.1080/0 0224499.2016.1259386

9. Riska E. Aging men: Resisting and endorsing medicalization. In: Kampf A, Marshall BL, Petersen A, eds. Aging Men, Masculinities, and Modern Medicine. London: Routlegde; 2013:71-85.

10. Vainionpää K, Topo P. The construction of male menopause in Finnish popular magazines. Crit Public Health. 2006;16(1):19-34. doi:10.1080/09581590600601882

11. Conrad P. Medicalization and social control. Annu Rev Sociol. 1992;18(1):209-232. doi:10.1146/annurev.so.18.080192.001233

12. Ballard K, Elston MA. Medicalisation: a multi-dimensional concept. Soc Theory Health. 2005;3(3):228-241. doi:10.1057/palgrave. sth. 8700053

13. Conrad P. The shifting engines of medicalization. $J$ Health Soc Behav. 2005;46(1):3-14. doi:10.1177/002214650504600102

14. Earp BD, Sandberg A, Savulescu J. The medicalization of love. Camb Q Healthc Ethics. 2015;24(3):323-336. doi:10.1017/ s0963180114000206

15. Sadler JZ, Jotterand F, Lee SC, Inrig S. Can medicalization be good? Situating medicalization within bioethics. Theor Med Bioeth. 2009;30(6):411-425. doi:10.1007/s11017-009-9122-4

16. Hofmann B. Medicalization and overdiagnosis: different but alike. Med Health Care Philos. 2016;19(2):253-264. doi:10.1007/s11019016-9693-6

17. Abraham J. Pharmaceuticalization of society in context: theoretical, empirical and health dimensions. Sociology. 2010;44(4):603-622. doi: $10.1177 / 0038038510369368$

18. Clarke AE, Shim JK, Mamo L, Fosket JR, Fishman JR. Biomedicalization: Technoscientific Transformations of Health, IIIness, and U.S. Biomedicine. Am Sociol Rev. 2003;68(2):161-194. doi: $10.2307 / 1519765$

19. Bell SE, Figert AE. Medicalization and pharmaceuticalization at the intersections: Looking backward, sideways and forward. Soc Sci Med. 2012;75(5):775-783. doi:10.1016/j.socscimed.2012.04.002

20. Conrad P. Medicalization: Changing Contours, Characteristics, and Contexts. In: Cockerham W, ed. Medical Sociology on the Move. Dordrecht: Springer Science + Business Media; 2013:195-214.

21. Buffel V, Dereuddre R, Bracke P. Medicalization of the uncertainty? An empirical study of the relationships between unemployment or job insecurity, professional care seeking, and the consumption of antidepressants. Eur Sociol Rev. 2015;31(4):446-459. doi:10.1093/ esr/jcv004

22. Buffel V, van de Straat V, Bracke P. Employment status and mental health care use in times of economic contraction: a repeated crosssectional study in Europe, using a three-level model. Int J Equity Health. 2015;14:29. doi:10.1186/s12939-015-0153-3

23. Moloney ME, Konrad TR, Zimmer CR. The medicalization of sleeplessness: a public health concern. Am J Public Health. 2011;101(8):1429-1433. doi:10.2105/ajph.2010.300014

24. Hislop J, Arber S. Understanding women's sleep management: beyond medicalization-healthicization? Sociol Health IIIn. 2003;25(7):815837.

25. Rafalovich A. Attention deficit-hyperactivity disorder as the medicalization of childhood: challenges from and for Sociology. Sociol Compass. 2013;7(5):343-354. doi:10.1111/soc4.12034

26. Singh I, Wessely S. Childhood: a suitable case for treatment? Lancet Psychiatry. 2015;2(7):661-666. doi:10.1016/s2215-0366(15)00106-6

27. Ekman I. Beyond medicalization: Self-injuring acts revisited. Health (London). 2016;20(4):346-362. doi:10.1177/1363459316633280

28. Gøtzsche PC, Jørgensen KJ, Krogsbøll LT. General health checks don't work. BMJ. 2014;348:g3680. doi:10.1136/bmj.g3680

29. Shostak S, Conrad P, Horwitz AV. Sequencing and its consequences: path dependence and the relationships between genetics and medicalization. AJS. 2008;114 Suppl:S287-316.

30. Levac D, Colquhoun H, O'Brien KK. Scoping studies: advancing the methodology. Implement Sci. 2010;5:69. doi:10.1186/1748-5908-5-69

31. Arksey H, O'Malley L. Scoping studies: towards a methodological framework. Int J Soc Res Methodol. 2005;8(1):19-32. doi:10.1080/1 364557032000119616

32. Freese J, Peterson D. Replication in social science. Annu Rev Sociol. 2017;43(1):147-165. doi:10.1146/annurev-soc-060116-053450

33. Barker KK. Electronic support groups, patient-consumers, and medicalization: the case of contested illness. J Health Soc Behav. 2008;49(1):20-36. doi:10.1177/002214650804900103

34. Barker KK. Listening to Lyrica: contested illnesses and pharmaceutical determinism. Soc Sci Med. 2011;73(6):833-842. doi:10.1016/j. socscimed.2011.05.055

35. Barker KK. Mindfulness meditation: do-it-yourself medicalization of every moment. Soc Sci Med. 2014;106:168-176. doi:10.1016/j. socscimed.2014.01.024

36. Clarke JN, Lang L. Mothers whose children have ADD/ADHD discuss their children's medication use: an investigation of blogs. Soc Work Health Care. 2012;51(5):402-416. doi:10.1080/00981389.2012.6605 67

37. Clarke JN. Medicalisation and changes in advice to mothers about children's mental health issues 1970 to 1990 as compared to 1991 to 2010: evidence from Chatelaine magazine. Health Risk Soc. 2013;15(5):416-431. doi:10.1080/13698575.2013.802295

38. Vainionpää K, Topo P. The making of an ageing disease: the representation of the male menopause in Finnish medical literature. Ageing Soc. 2005;25(6):841-861. doi:10.1017/S0144686X05003946

39. Bell AV. Beyond (financial) accessibility: inequalities within the medicalisation of infertility. Sociol Health IIIn. 2010;32(4):631-646. doi:10.1111/j.1467-9566.2009.01235.x

40. Padamsee TJ. The pharmaceutical corporation and the 'good work' of managing women's bodies. Soc Sci Med. 2011;72(8):1342-1350. doi:10.1016/j.socscimed.2010.10.034 
41. Bransen E. Has menstruation been medicalised? Or will it never happen. Sociol Health IIIn. 1992;14(1):98-110. doi:10.1111/14679566.ep11007176

42. Williams SJ, Seale C, Boden S, Lowe P, Steinberg DL. Medicalization and beyond: the social construction of insomnia and snoring in the news. Health (London). 2008;12(2):251-268. doi:10.1177/1363459307086846

43. Becker G, Nachtigall RD. Eager for medicalisation: the social production of infertility as a disease. Sociol Health IIIn. 1992;14(4):456471.

44. Gammell DJ, Stoppard JM. Women's experiences of treatment of depression: Medicalization or empowerment? Can Psychol. 1999;40(2):112-128. doi:10.1037/h0086831

45. Holmqvist M. Medicalization of unemployment: individualizing social issues as personal problems in the Swedish welfare state. Work Employ Soc. 2009;23(3):405-421. doi:10.1177/0950017009337063

46. Hyde A, Treacy MM, Scott AP, et al. Social regulation, medicalisation and the nurse's role: insights from an analysis of nursing documentation. Int J Nurs Stud. 2006;43(6):735-744. doi:10.1016/j. ijnurstu.2005.10.001

47. Westfall RE, Benoit C. The rhetoric of "natural" in natural childbirth: childbearing women's perspectives on prolonged pregnancy and induction of labour. Soc Sci Med. 2004;59(7):1397-1408. doi:10.1016/j.socscimed.2004.01.017

48. Arney J, Rafalovich A. Incomplete syllogisms as techniques of medicalization: The case of direct-to-consumer advertising in popular magazines, 1997 to 2003. Qual Health Res. 2007;17(1):49-60. doi:10.1177/1049732306293778

49. Barker KK. Mindfulness meditation: do-it-yourself medicalization of every moment. Soc Sci Med. 2014;106:168-176. doi:10.1016/j. socscimed.2014.01.024

50. Elston MA, Gabe J, Denney D, Lee R, O'Beirne M. Violence against doctors: a medical(ised) problem? The case of National Health Service general practitioners. Sociol Health IIIn. 2002;24(5):575-598. doi:10.1111/1467-9566.00309

51. Adams J. Medicalization and the market economy: Constructing cosmetic surgery as consumable health care. Sociol Spectr. 2013;33(4):374-389. doi:10.1080/02732173.2013.732895

52. Coveney CM, Nerlich B, Martin P. Modafinil in the media: metaphors, medicalisation and the body. Soc Sci Med. 2009;68(3):487-495. doi:10.1016/j.socscimed.2008.11.016

53. Hogle LF. Chemoprevention for healthy women: harbinger of things to come? Health. 2001;5(3):311-333. doi:10.1177/136345930100500303

54. Jacob JD, Gagnon M, McCabe J. From distress to illness: a critical analysis of medicalization and its effects in clinical practice. J Psychiatr Ment Health Nurs. 2014;21(3):257-263. doi:10.1111/jpm.12078

55. Parry DC. "We wanted a birth experience, not a medical experience": exploring Canadian women's use of midwifery. Health Care Women Int. 2008;29(8):784-806. doi:10.1080/07399330802269451

56. Kilty JM. 'It's like they don't want you to get better': Psy control of women in the carceral context. Fem Psychol. 2012;22(2):162-182. doi:10.1177/0959353512439188

57. Lee E, Macvarish J, Sheldon S. Assessing child welfare under the Human Fertilisation and Embryology Act 2008: a case study in medicalisation? Sociol Health IIIn. 2014;36(4):500-515. doi:10.1111/1467-9566.12078

58. Malacrida C. Medicalization, ambivalence and social control: mothers' descriptions of educators and ADD/ADHD. Health (London). 2004;8(1):61-80. doi:10.1177/1363459304038795

59. Merianos AL, Vidourek RA, King KA. Medicalization of female beauty: a content analysis of cosmetic procedures. Qual Rep. 2013;18(46):114.

60. Neiterman E. Sharing bodies: the impact of the biomedical model of pregnancy on women's embodied experiences of the transition to motherhood. Healthc Policy. 2013;9(Spec Issue):112-125.

61. Polonijo AN, Carpiano RM. Representations of cosmetic surgery and emotional health in women's magazines in Canada. Womens Health Issues. 2008;18(6):463-470. doi:10.1016/j.whi.2008.07.004
62. Schierenbeck I. Medicalization of sickness absence. Work. 2010;37(3):241-250. doi:10.3233/wor-2010-1076

63. Torres JMC. Medicalizing to demedicalize: Lactation consultants and the (de)medicalization of breastfeeding. Soc Sci Med. 2014;100:159166. doi:10.1016/j.socscimed.2013.11.013

64. Venn S, Meadows R, Arber S. Gender differences in approaches to self-management of poor sleep in later life. Soc Sci Med. 2013;79:117123. doi:10.1016/j.socscimed.2012.09.037

65. Binney EA, Estes CL, Ingman SR. Medicalization, public policy and the elderly: social services in jeopardy? Soc Sci Med. 1990;30(7):761-771. doi:10.1016/0277-9536(90)90199-3

66. Fainzang $\mathrm{S}$. The other side of medicalization: self-medicalization and self-medication. Cult Med Psychiatry. 2013;37(3):488-504. doi:10.1007/s11013-013-9330-2

67. McLeod JD, Pescosolido BA, Takeuchi DT, White TF. Public attitudes toward the use of psychiatric medications for children. $J$ Health Soc Behav. 2004;45(1):53-67. doi:10.1177/002214650404500104

68. Selin J. Implementation of substitution treatment in Finland: Beyond rationalisation and medicalisation. Nord Stud Alcohol Drugs. 2011;28(1):29-42. doi:10.2478/v10199-011-0003-6

69. Boero N. All the news that's fat to print: The American "obesity epidemic" and the media. Qual Sociol. 2007;30(1):41-60. doi:10.1007/ s11133-006-9010-4

70. Van Brummen B, Griffiths L. Working in a medicalised world: the experiences of palliative care nurse specialists and midwives. Int $J$ Palliat Nurs. 2013;19(2):85-91. doi:10.12968/ijpn.2013.19.2.85

71. Harvey K. Medicalisation, pharmaceutical promotion and the Internet: a critical multimodal discourse analysis of hair loss websites. Social Semiotics. 2013;23(5):691-714. doi:10.1080/10350330.2013.777596

72. Norris P, Horsburgh S, Lovelock K, et al. Medicalisation or undertreatment? Psychotropic medication use by elderly people in New Zealand. Health Sociol Rev. 2011;20(2):202-218. doi:10.5172/ hesr.2011.20.2.202

73. Thomas-MacLean R. Memories of treatment: the immediacy of breast cancer. Qual Health Res. 2004;14(5):628-643. doi:10.1177/1049732304263658

74. Melick ME, Steadman HJ, Cocozza JJ. The medicalization of criminal behavior among mental patients. J Health Soc Behav. 1979;20(3):228237.

75. Rafalovich A. Relational Troubles and Semiofficial Suspicion: Educators and the Medicalization of "Unruly" Children. Symb Interact. 2005;28(1):25-46. doi:10.1525/si.2005.28.1.25

76. Oinas E. Medicalisation by Whom? Accounts of Menstruation Conveyed by Young Women and Medical Experts in Medical Advisory Columns. Sociol Health IIIn. 1998;20(1):52-70. doi:10.1111/14679566.00080

77. Calnan M. Women and medicalisation: an empirical examination of the extent of women's dependence on medical technology in the early detection of breast cancer. Soc Sci Med. 1984;18(7):561-569. doi:10.1016/0277-9536(84)90071-6

78. Brubaker SJ. Denied, embracing, and resisting medicalization: African American teen mothers' perceptions of formal pregnancy and childbirth care. Gend Soc. 2007;21(4):528-552.

79. Chang VW, Christakis NA. Medical modelling of obesity: a transition from action to experience in a 20th century American medical textbook. Sociol Health IIIn. 2002;24(2):151-177. doi:10.1111/1467-9566.00289

80. Hislop J, Arber S. Understanding women's sleep management: beyond medicalization-healthicization? Sociol Health IIIn. 2003;25(7):815837.

81. Moreira T. Sleep, health and the dynamics of biomedicine. Soc Sci Med. 2006;63(1):54-63. doi:10.1016/j.socscimed.2005.11.066

82. Moloney ME, Konrad TR, Zimmer CR. The medicalization of sleeplessness: a public health concern. Am J Public Health. 2011;101(8):1429-1433. doi:10.2105/ajph.2010.300014

83. Williams SJ, Seale C, Boden S, Lowe P, Steinberg DL. Medicalization and beyond: the social construction of insomnia and snoring in the news. Health (London). 2008;12(2):251-268. doi:10.1177/1363459307086846 